\title{
Acceso a la Universidad de Salamanca del estudiantado con discapacidad
}

\author{
José Ángel Gallego González; José Lorenzo García Sánchez; \\ Rocío Galache Iglesias; Víctor Tejedor Hernández
}

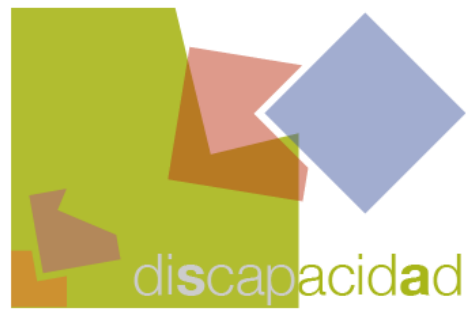

e trata de una iniciativa que busca proporcionar un acompañamiento a los estudiantes de último curso de Bachillerato que se presentan a las pruebas de acceso a estudios universitarios.

Este acompañamiento lo proporciona la Unidad de Apoyo a la Comunidad Universitaria con Discapacidad del Servicio de Asuntos Sociales de la Universidad de Salamanca.

La Unidad de Apoyo de la Comunidad Universitaria con Discapacidad realiza las siguientes funciones:

- Apoyo, orientación, asesoramiento en materia de discapacidad.

- Facilitación de los productos de apoyo necesarios para el acceso a la comunicación.

- Elaboración de un proyecto de adecuación de los espacios físicos y entornos web accesibles.

- Formación y búsqueda de recursos en materia de discapacidad.

- Apoyo en el área laboral.

La labor de apoyo y orientación al estudiantado con discapacidad se lleva a cabo en los centros educativos con el fin de informar a los estudiantes, profesores y familias acerca de los recursos y apoyos que existen.

Los técnicos de la Unidad asesoran a los estudiantes antes de las pruebas de acceso y durante las mismas, así como en su etapa universitaria. 
Gracias a este acompañamiento proporcionado por la Unidad y a los cambios en la legislación, han aumentado considerablemente los casos atendidos por la Unidad desde el año 2005.

La USAL brinda apoyo a los estudiantes con discapacidad en las etapas previas a la universidad, proporcionando formación y asesoramiento a todos los centros educativos a partir de los 15 años e incluso para mayores de 25, 40 y 45 años.

La Unidad valora y propone las adaptaciones curriculares necesarias para los estudiantes que se presentan a las pruebas selectivas de acceso a la universidad.

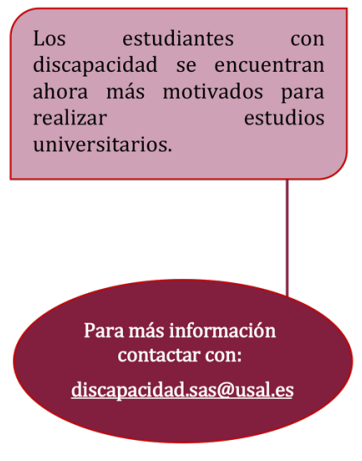

Las medidas podrán consistir en:

- Adaptación de los tiempos.

- Medios materiales y humanos y productos de apoyo que precise el estudiante para la realización de las pruebas.

- Accesibilidad a la información y la comunicación (Intérprete de LSE y Apoyo Oral).

- Accesibilidad del recinto o espacio físico donde se desarrollen las pruebas.

La divulgación se realiza desde los centros escolares, para que los estudiantes conozcan la existencia de un servicio que les presta apoyo durante la realización de las pruebas de acceso a la universidad y durante el transcurso de sus estudios en la misma. 